\title{
Dimensi Interaksi Penyedia-Penerima dalam Perkhidmatan Sokongan Sosial untuk Pembangunan Syarikat PKS: Kajian Kes Majlis Amanah Rakyat (MARA)
}

(Dimensions of Provider-Recipient Interaction in Social Support Service for SME Development: Case Study of Majlis Amanah Rakyat (MARA))

\author{
Shahrizin Abdul Sarhadat \\ (Majlis Amanah Rakyat) \\ Khairul Akmaliah Adham \\ (Fakulti Ekonomi dan Muamalat, Universiti Sains IslamMalaysia) \\ Rosmah Mat Isa \\ (Fakulti Ekonomi dan Pengurusan, Universiti Kebangsaan \\ Malaysia)
}

ABSTRAK

\begin{abstract}
Interaksi dalam perkhidmatan antara penyedia dan penerima telah banyak dibincangkan dalam kajian yang lepas. Walau bagaimanapun, terdapat jurang pengetahuan tentang interaksi dalam konteks perkhidmatan sosial yang menyokong pemberdayaan golongan terpinggir dalam masyarakat. Lebih-lebih lagi bagi perkhidmatan yang melibatkan kos yang besar kepada pembayar cukai bagi menyokong mandat membasmi kemiskinan dalam negara dan meningkatkan keterangkuman untuk semua lapisan masyarakat. Maka, pengetahuan tentang dimensi interaksi dalam perkhidmatan sosial ini dilihat sebagai suatu yang mustahak. Justeru, objektif kajian ini adalah untuk mengenalpasti dimensi interaksi penyedia-penerima dalam perkhidmatan sosial yang disediakan oleh Majlis Amanah Rakyat (MARA) iaitu sebuah agensi sosial terbesar di Malaysia. Bagi mencapai objektif kajian, kaedah penyelidikan kualititatif berbentuk triadik telah digunakan yang melibatkan temubual dengan pihak penyedia dan penerima perkhidmatan. Kerangka kajian dibina berasaskan perspektif pengurusan perkhidmatan, organisasi sosial serta model kitaran hayat organisasi yang mengenengahkan keperluan interaksi yang aktif antara penyedia-penerima bagi memastikan perkhidmatan yang berkesan. Kajian mendapati terdapat empat belas dimensi interaksi dalam perkhidmatan sosial yang menyokong pembangunan syarikat dan pembangunan pengalaman dan pengetahuan kepada pihak penyedia perkhidmatan. Dapatan kajian menyumbang kepada pembangunan teori pengurusan perkhidmatan dalam konteks perkhidmatan sosial dengan menekankan pembangunan PKS sebagai suatu proses yang harus disokong oleh interaksi penyedia-penerima yang simbiotik yang berkembang sejajar dengan kitaran hayat syarikat PKS bagi memastikan pembangunan firma yang lebih utuh.
\end{abstract}

Kata kunci: Interaksi; pengurusan perkhidmatan; perkhidmatan sokongan social; pembangunan PKS; MARA.

\section{ABSTRACT}

Service interactions between providers and service providers have been widely discussed in previous studies. However, there is a dearth of research on interactions in the context of social service that support empowerment of marginalized groups in society. This gap must be addressed particularly when such service is taxpayer-funded that support poverty alleviation and increased inclusiveness for all in society. Hence, the objective of this study is to identify the dimensions of provider-recipient interaction in social service provided by the People's Trust Council (MARA), the largest social organization in Malaysia. To achieve the objective of the study, the study adopted a triadic qualitative research methodology which involved interviews of both service providers and service recipients. The study's research framework is built on the perspectives of service management, social organization and organizational life cycle model that emphasize the need for active interactions between providers to ensure effective delivery of service. The study identified fourteen dimensions of interaction in social service that support both development of SME and personal experience and development of knowledge of the service provider side. The findings of this study contribute to service management theory in the context of social service by emphasizing the development of SMEs as a process that should be supported by symbiotic providerrecipient interactions that evolve in line with the life cycle of the companies to ensure a more robust firm development.

Keywords: Interaction; service management; social support service; SME development; MARA 


\section{PENDAHULUAN}

Menurut teori pengurusan perkhidmatan, sesuatu penyampaian perkhidmatan memerlukan interaksi yang aktif antara kedua-dua belah pihak penyedia dan penerima perkhidmatan bagi membolehkan proses perkhidmatan yang memberi manfaat untuk kedua-dua belah pihak (Sampson \& Froehle 2006). Berasaskan pandangan ini, interaksi yang aktif antara kedua-dua belah pihak penyedia dan penerima turut menjadi penting dalam memastikan keberkesanan perkhidmatan sokongan sosial. Perkhidmatan sokongan sosial dalam konteks kajian ini adalah merujuk kepada perkhidmatan sokongan sosial yang dilaksanakan oleh Majlis Amanah Rakyat (MARA), sebuah agensi yang beroperasi di bawah Kementerian Pembangunan Luar Bandar (KPLB). Perkhidmatan sokongan sosial ini merupakan salah satu pendekatan utama untuk merealisasikan pembangunan syarikat Perusahaan Kecil dan Sederhana (PKS) yang menjadi mandat utama organisasi MARA.

Antara perkhidmatan sokongan sosial yang ditawarkan oleh MARA untuk pembangunan syarikat PKS adalah latihan keusahawanan, pembangunan pemasaran, pembangunan standard perniagaan, pembiayaan perniagaan, dan penyewaan premis perniagaan. Perkhidmatan sokongan sosial yang ditawarkan ini khususnya program sokongan berbentuk standard, sebahagian besarnya diberikan secara percuma. Manakala perkhidmatan yang lain akan dikenakan bayaran kesungguhan (earnest fee). Perkhidmatan sokongan sosial berbentuk lanjutan atau pelangganan yang ditawarkan dikenakan fi atau caj mengikut nisbah sumbangan penerima perkhidmatan yang ditentukan oleh pihak MARA (MARA 2015).

Perkhidmatan sokongan ini membolehkan syarikat PKS mengurangkan beban kos kewangan syarikat berbanding dengan beban kos kewangan mendapatkan perkhidmatan yang sama daripada bank atau institusi kewangan komersial. Situasi ini menjadikan skim pembiayaan perniagaan yang ditawarkan oleh MARA sebagai alternatif penyelesaian masalah terbaik untuk menangani isu kesukaran syarikat PKS, terutamanya bagi syarikat baharu dalam mendapatkan dana perniagaan (MARA 2015). Sebagai nilai tambah, biaya perniagaan MARA ini diikuti dengan penasihatan yang bukan sahaja menyumbang kepada proses pembangunan PKS yang lebih mapan, malah membolehkan pihak MARA untuk mengelak dari kemungkinan kegagalan pembayaran balik biaya perniagaan. Sehubungan itu, perkhidmatan sokongan sosial yang dibangunkan oleh MARA dilihat amat mustahak untuk memenuhi keperluan pembangunan syarikat PKS, agar dapat menyumbang kepada pembangunan diri usahawan, pembangunan firma mereka, dan seterusnya menyumbang kepada pembangunan industri dan ekonomi negara.

Walaupun para sarjana bidang pengurusan menekankan keperluan kepada interaksi yang aktif antara keduadua belah pihak penyedia dan penerima perkhidmatan dalam sesuatu proses perkhidmatan, sehingga kini, kajian mengenainya masih kurang diberi tumpuan (Gheduzzi et al. 2020) terutama dalam konteks perkhidmatan awam (Van de Walle 2016). Ternyata bahawa teori dan perspektif sedia ada belum lengkap untuk menjelaskan sepenuhnya tentang interaksi dalam perkhidmatan sokongan sosial yang matlamat utamanya ialah pembangunan sosial. Situasi kelompangan teoretikal ini boleh mengakibatkan pelaksanaan perkhidmatan sokongan sosial gagal atau tidak berkesan, yang akhirnya boleh memberi impak yang negatif terutamanya bagi yang dilaksanakan secara berskala besar dan berkos tinggi, seperti dalam konteks organisasi MARA. Bagi mengatasi jurang ini, kajian ini bertujuan mengenalpasti dimensi interaksi dalam proses penyampaian perkhidmatan sokongan sosial MARA sebagai penyedia perkhidmatan, khususnya untuk pembangunan syarikat PKS, dan usahawan syarikat PKS sebagai penerima perkhidmatan.

\section{SOROTAN LITERATUR -PERSPEKTIF DAN TEORI ASAS KAJIAN}

Kajian ini melihat perkhidmatan sokongan sosial bertujuan untuk menyokong pembangunan syarikat PKS yang ditawarkan oleh organisasi penyedia perkhidmatan sokongan sosial iaitu Majlis Amanah Rakyat (MARA), sebuah agensi milik Kerajaan, yang penerimanya adalah dalam kalangan usahawan. Dalam konteks ini, kumpulan yang menjadi fokus dalam kajian ialah organisasi penyedia perkhidmatan sokongan (MARA), dan ejen (pegawai MARA), serta penerima perkhidmatan, yakni usahawan PKS dan firma mereka. Dalam konteks ini, teori-teori asas yang mendasari kajian ini adalah konsep pengurusan perkhidmatan, organisasi sosial dan ejen sebagai penyedia perkhidmatan sosial, perspektif keusahawanan dan model kitaran hayat organisasi.

\section{KONSEP PENGURUSAN PERKHIDMATAN}

Regan (1963) memperkenalkan definisi perkhidmatan sebagai aktiviti, faedah atau kepuasan yang ditawarkan untuk dijual dan disediakan bersama-sama dengan penjualan produk. Manakala Lusch dan Vargo (2006) pula mendefinisikan perkhidmatan sebagai penggunaan kompetensi khusus iaitu pengetahuan dan kemahiran melalui tindakan, proses dan pelaksanaan yang memberi manfaat kepada kedua-dua pihak penyedia dan penerima perkhidmatan. Seterusnya Lusch dan Vargo (2006) menyatakan bahawa penyampaian perkhidmatan dilaksanakan dalam bentuk hubungan yang rapat antara penyedia dengan pelanggan, yang berasaskan pengetahuan dan penyediaan perkhidmatan yang disesuaikan dengan keperluan penerima perkhidmatan. 
Sampson dan Froehle (2006) pula menambah bahawa proses perkhidmatan bergantung kepada input dan penyertaan pelanggan atau penerima perkhidmatan serta pembekal perkhidmatan lain yang menyumbang sumber tenaga kerja, infrastruktur dan maklumat bagi tujuan penyediaan pakej perkhidmatan. Faktor-faktor inilah yang akan menentukan keberkesanan proses interaksi antara penyedia dan penerima (Gheduzzi et al. 2020). Akhirnya Vargo (2008) meluaskan definisi perkhidmatan sebagai penggunaan sumber pembekal untuk faedah pelanggan atau penerima perkhidmatan dan pihak yang berkepentingan.

Bitner, Fisk dan Brown (1993) menggariskan empat ciri utama perkhidmatan iaitu ketidakketaraan (intangibility), tidak dapat dipisahkan (inseparability), keanekajenisan atau berbeza-beza (heterogeneity) dan lekas musnah (perishability). Antara ciri utama perkhidmatan yakni, perkhidmatan yang ditawarkan kepada pengguna adalah tidak dapat dipisahkan daripada penyedia perkhidmatan, menunjukkan kepentingan interaksi aktif di antara penyedia dan pengguna. Ini bererti suatu proses perkhidmatan tidak boleh wujud secara sebelah pihak sepenuhnya kerana selalunya akan terdapat satu ketika apabila interaksi antara penyedia dan penerima perkhidmatan berlaku secara langsung (Bowen 1990; Onkvisit \& Shaw 1991). Proses interaksi yang berkesan akan menghasilkan pengeluaran secara bersama yang dapat meningkatkan kepuasan atau sebaliknya. Justeru, proses interaksi ini memberikan suatu peluang bagi pengguna menilai prestasi serta kualiti perkhidmatan yang diterimanya (Grönroos 1978; Zeithaml 1981).

Kajian ini mendefinisikan perkhidmatan sebagai penyediaan perkhidmatan sokongan sosial oleh organisasi penyedia perkhidmatan dengan menggunakan sumber dalaman dan luaran organisasi berkenaan untuk penerima perkhidmatan sokongan iaitu syarikat PKS bagi tujuan pembangunan syarikat mereka. Selain itu, penyediaan perkhidmatan ini juga adalah untuk manfaat kedua-dua belah pihak iaitu penyedia dan penerima perkhidmatan.

\section{MODEL KITARAN HAYAT ORGANISASI}

Kajian ini menggunakan model kitaran hayat oleh Daft (2013) sebagai salah satu perspektif dalam membangun kerangka konseptual kajian interaksi sosial penyedia-penerima. Kebanyakan model kitaran hayat yang dibangunkan oleh pengkaji yang lalu berbeza dari segi ciri-ciri dan bilangan tahap, bagaimanapun kebanyakan model yang dibangunkan ini mempunyai empat tahap secara tertib iaitu kelahiran, pertumbuhan, kematangan, kebangkitan semula (Miller \& Frieson 1980). Kajian ini menggunakan secara adaptasi model kitaran hayat organisasi oleh Daft (2013), yang mengenengahkan empat tahap pembangunan organisasi, iaitu keusahawanan, kelompokan, pemformalan dan perluasan.

Tahap Keusahawanan Menurut Daft (2013), organisasi yang berada di tahap keusahawanan ini adalah organisasi yang baharu ditubuhkan. Di tahap ini, fokus utama organisasi adalah kepada penghasilan produk atau perkhidmatan. Maka, pengasas atau usahawan atau pemilik organisasi memberikan sepenuh perhatian kepada aktiviti pembangunan dan pemasaran produk atau perkhidmatan. Pada tahap ini, operasi firma dan aktiviti pengawalannya adalah informal. Pada tahap ini, organisasi akan bergantung kepada organisasi luar untuk mendapatkan sumber yang kritikal (Jawahar \& McLaughlin 2001). Kreativiti dalam pembangunan produk atau perkhidmatan dan kepimpinan organisasi yang mantap menjadi keperluan penting organisasi dalam tahap ini, yang hasil utamanya ialah pengeluaran dan pemasaran produk atau perkhidmatan yang baharu.

Tahap Kelompokan Menurut Daft (2013), setelah organisasi berjaya menghasilkan produk atau perkhidmatan, organisasi mula menetapkan matlamat dan arah tujunya dengan lebih jelas. Bagi tujuan ini, organisasi mula membangun sistem kawalan asas dan merekabentuk struktur organisasi termasuk hirarki kuasa. Seterusnya, menurut Daft (2013) lagi, dengan adanya matlamat dan struktur, kakitangan organisasi mempunyai hala tuju yang lebih jelas untuk melaksanakan peranan dan tugas masing-masing, dan mula mempunyai rasa kekitaan dalam organisasi. Pada tahap ini, kemungkinan berlaku krisis berkenaan pembuatan keputusan organisasi yang masih berpusat di peringkat atasan. Justeru, bagi mengatasi krisis dan melepasi tahap ini, organisasi perlu melaksanakan koordinasi antara bahagian serta membentuk sistem penurunan kuasa yang lebih sistematik.

Tahap Pemformalan Seterusnya menurut Daft (2013), organisasi yang berada di tahap pemformalan ini telahpun mempunyai struktur dan sistem kawalan yang formal. Pembahagian struktur yang jelas membolehkan pengurusan atasan organisasi memberi tumpuan kepada isu-isu di peringkat strategik, manakala urusan di peringkat operasi dibuat oleh pihak pengurusan pertengahan. Koordinasi di antara bahagian dan unit menjadi mantap dan insentif berasaskan keuntungan organisasi mula diperkenalkan kepada kakitangan. Krisis yang berlaku di tahap pemformalan ini adalah berkenaan peningkatan karenah birokrasi yang boleh mengakibatkan organisasi mengalami pelbagai masalah pentadbiran. Masalah karenah birokrasi ini perlu diselesaikan melalui pembudayaan kolaborasi antara bahagian dan semangat kerja berpasukan dalam organisasi.

Tahap perluasan Akhirnya menurut Daft (2013), pada tahap perluasan ini, organisasi meneruskan usaha mengurus masalah birokrasi dengan lebih cekap bagi mengelak sama sekali situasi kemerosotan organisasi. Usaha 
termasuk mengukuhkan kedudukan dan reputasi organisasi dan mengelak rasa kepuasan dengan prestasi semasa. Berdasarkan model kitaran hayat pembangunan organisasi, organisasi penyedia perkhidmatan sokongan sosial perlu melihat kesesuaian perkhidmatan yang ditawarkan kepada penerima perkhidmatan sokongan sosial dengan tahap pembangunan syarikat PKS mereka.

\section{ORGANISASI PENYEDIA PERKHIDMATAN SOSIAL-MAJLIS AMANAH RAKYAT}

Dalam konteks kajian ini, organisasi perkhidmatan sokongan merujuk kepada organisasi penyedia perkhidmatan sokongan sosial iaitu Majlis Amanah Rakyat (MARA). Perkhidmatan sokongan sosial yang ditawarkan oleh MARA kepada syarikat PKS termasuk latihan keusahawanan, pembangunan standard perniagaan, pembangunan pemasaran, pembiayaan perniagaan dan penyewaan premis perniagaan dan sebagainya. Untuk melaksanakan perkhidmatan sokongan tersebut, pegawai MARA adalah ejen pemberi perkhidmatan.

Berasaskan kepada Iturralde et al. (2007), ejen dalam konteks kajian ini didefinisikan sebagai individu atau kumpulan individu yang memberikan perkhidmatan dan mewujudkan hubungan antara penyedia dan penerima perkhidmatan. Kajian lepas menunjukkan tahap penglibatan ejen dalam proses perkhidmatan sokongan sosial adalah berbeza-beza. Menurut Lamb dan Kling (2003), penglibatan ejen di peringkat awal program hanya memberikan maklumat yang relevan tentang rangka program perkhidmatan sokongan sosial sedia ada yang sedang dibangunkan. Manakala di peringkat lanjutan, ejen dilibatkan untuk memberikan pandangan mengenai program dan bersama-sama bertanggungjawab dalam pelaksanaan dan pemantauan program tersebut. Sementara itu pula, Fieldler (1964) menegaskan bahawa ejen perlu memadankan gaya mereka dengan keperluan situasi beza mengikut tahap kematangan penerima kemudahan dan perubahan keperluan perniagaan mereka.

\section{USAHAWAN PKS SEBAGAI PENERIMA PERKHIDMATAN SOKONGAN SOSIAL}

Shane dan Ventakaram (2000) menekankan keusahawanan sebagai kumpulan individu yang mempunyai sifat merebut peluang dan mencari keuntungan. Dalam konteks kajian ini, usahawan adalah pemilik atau pengurus di syarikat PKS yang berusaha untuk mencari dan menerima perkhidmatan sokongan sosial yang disediakan oleh organisasi penyedia perkhidmatan sokongan bagi memenuhi keperluan pembangunan syarikat mereka. Secara dasarnya, kedua-dua belah pihak penyedia dan penerima perkhidmatan akan bergantung kepada penyertaan secara demokratik untuk mencapai matlamat msing-masing (Jaumier 2017). Ini bermakna, bagi perkhidmatan sosial, penerima juga merupakan pengeluar bersama (co-producer) kepada perkhidmatan yang diberikan (Osborne 2018)

\section{KERANGKA KONSEPTUAL KAJIAN}

Kerangka konseptual kajian dalam Rajah 1 menunjukkan interaksi penyedia-penerima perkhidmatan sokongan sosial untuk pembangunan syarikat PKS. Ejen penyedia dalam perkhidmatan menghubungkan perkhidmatan yang dibangunkan oleh organisasi penyedia perkhidmatan, yakni MARA, untuk memenuhi keperluan penerima sasaran perkhidmatan, iaitu syarikat PKS. Hubungan interaksi antara penyedia-penerima perkhidmatan dijangka berlaku secara dua hala dalam proses penyampaian dan penerimaan perkhidmatan sokongan sosial.

Proses perkhidmatan bermula dengan ejen menjalankan kerja-kerja mengenal pasti keperluan termasuk masalah yang dihadapi oleh syarikat PKS melalui rekod dan dokumen yang berkaitan. Seterusnya, hasil analisis keperluan digunakan oleh ejen untuk proses seterusnya, iaitu fasa reka bentuk program yang ditawarkan oleh organisasi penyedia perkhidmatan sokongan sosial. Fasa ini membolehkan organisasi penyedia perkhidmatan sokongan sosial merangka secara terperinci program pembangunan syarikat PKS yang dilaksanakan dan fasa ini dijangka berlaku sebelum hubungan terus dengan syarikat PKS bermula.

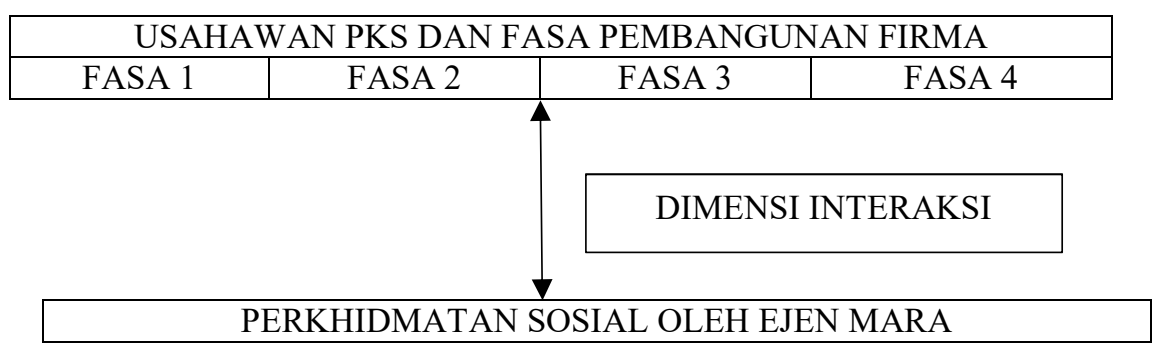

RAJAH 1. Kerangka konseptual kajian 
Tindakan seterusnya adalah ejen melaksanakan program perkhidmatan sokongan sosial yang telah dirancang dengan menyampaikannya kepada syarikat PKS. Berasaskan kepada perspektif pengurusan perkhidmatan, fungsi ejen adalah untuk menghubungkan sumber (resources) organisasi penyedia perkhidmatan sokongan sosial untuk memenuhi keperluan syarikat PKS yang dikategorikan sebagai usahawan kecil dan sederhana mengikut takrifan SME Corp (2015). Dalam konteks perkhidmatan sosial, ejen berperanan sebagai pegawai pengembangan (extension officer) dalam melaksanakan tanggungjawab sosial terhadap syarikat PKS, dan disampaikan dalam bentuk perhubungan secara individu atau berkumpulan.

Bagi pihak penerima pula, menurut perspektif keusahawanan, usahawan bertanggungjawab sepenuhnya untuk mengenalpasti peluang perniagaan dan membangunkannya sebagai sebuah perniagaan. Bagi memastikan perkhidmatan sokongan sosial ini dapat dipertingkatkan pada masa akan datang, interaksi dengan pengguna perkhidmatan iaitu syarikat PKS dan keterlibatan mereka perlulah difahami dengan jelas (McLaughlin, Osborne \& Chew 2009). Kajian ini menggunakan model kitaran hayat organisasi yang terdiri daripada empat tahap dalam kitaran hayat syarikat PKS, iaitu, tahap keusahawanan, tahap kelompokan, tahap pemformalan dan tahap perluasan sebagai asas dalam menganalisis dimensi interaksi hubungan antara ejen dan syarikat PKS dalam setiap tahap pembangunan firma.

\section{METODOLOGI KAJIAN}

Bagi mencapai objektif kajian iaitu untuk mengenalpasti dimensi interaksi dalam proses perkhidmatan sokongan sosial untuk pembangunan syarikat PKS, kajian mengguna pakai reka bentuk penyelidikan kualitatif asas prosesual dengan kaedah temu bual triadik sebagai strategi penyelidikan (Muhamad et al. 2018). Kaedah triadik ini dipilih kerana keberkesanan interaksi sosial atau perkhidmatan yang diberikan oleh penyedia kepada penerima perlu dinilai dari segi prestasi serta kualiti perkhidmatan yang diberikan (Grönroos 1978; Zeithaml 1981). Dalam konteks kajian ini, penyelaras adalah pihak ketiga yang menilai penyedia perkhidmatan. Menurut Merriam (2009) kajian kualitatif asas adalah satu kaedah penerangan dan analisis yang mendalam mengenai sesuatu fenomena; dalam kajian ini, penyelidikan tertumpu kepada fenomena interaksi penyedia-penerima dalam konteks perkhidmatan sokongan sosial MARA.

Stern (1980) menambah kaedah kualitatif ini adalah bersesuaian dalam usaha meneroka bidang substantif yang belum diketahui atau yang pengetahuan boleh diperoleh melalui penjanaan pemahaman baharu. Manakala menurut Strauss dan Corbin (1998), kaedah kualitatif juga sesuai dalam mendapatkan maklumat yang rumit mengenai fenomena penyelidikan yang melibatkan perasaan, proses berfikir dan emosi yang sukar diperoleh atau dipelajari secara mendalam melalui kaedah penyelidikan kuantitatif. Maka tujuan penyelidikan ini adalah untuk memahami makna sesuatu fenomena melalui pengalaman individu yang telah melalui fenomena tersebut. Tambahan pula, menurut Pettigrew (1997) kajian kualititatif berbentuk prosesual memberi kelebihan dalam mengkaji sesuatu proses yang berlaku secara ubah-ansur (evolving). Khususnya dalam konteks kajian ini, matlamat penyelidikan ialah untuk mengenal pasti dimensi interaksi yang muncul dalam tempoh masa proses perkhidmatan sosial.

Sejajar dengan rekabentuk kajian triadik, temu bual secara terperinci telah dilaksanakan dengan pihak ejen dan pihak penerima perkhidmatan sokongan sosial dengan pemilihan peserta menggunakan persampelan bertujuan. Menurut Patton (1990), persampelan bertujuan adalah teknik persampelan bukan kebarangkalian (nonprobability). Peserta kajian yang dipilih adalah Pegawai MARA dan usahawan syarikat PKS yang terlibat secara langsung dengan perkhidmatan sokongan sosial untuk pembangunan syarikat PKS yang ditawarkan oleh organisasi penyedia perkhidmatan sokongan sosial iaitu Majlis Amanah Rakyat (MARA).

Peserta kajian terdiri daripada tiga kumpulan utama iaitu:

1. Pihak penyedia terdiri daripada Pegawai MARA Daerah, Penolong Pegawai MARA Daerah, pegawai yang secara langsung berurusan dengan syarikat PKS tersebut,

2. Pihak penyelaras iaitu Pegawai MARA di peringkat negeri atau Daerah yang merupakan penyelaras kepada Pegawai MARA yang berurusan dengan syarikat PKS.

3. Pihak penerima perkhidmatan sokongan sosial adalah syarikat PKS dalam sektor perkhidmatan dan perdagangan.

\section{KRITERIA PEMILIHAN SAMPEL PESERTA KAJIAN}

Pihak penyedia perkhidmatan terdiri daripada Pegawai MARA yang terlibat secara langsung dalam program pembangunan syarikat PKS dan mempunyai pengalaman bekerja lebih daripada lima (5) tahun. Pihak penyelaras pula adalah Pegawai MARA dari Pejabat MARA Negeri atau Daerah yang menjadi penyelaras dan menilai Pegawai MARA yang memberi perkhidmatan kepada usahawan PKS. Pegawai MARA ini terdiri daripada pegawai Kumpulan Pengurusan dan Profesional bergred 41 dan ke atas atau mana-mana staf kumpulan sokongan I bergred 36. 
Syarikat PKS adalah syarikat yang berusia tiga (3) tahun dan ke atas dan menerima sokongan sosial sekurang-kurangnya satu atau kesemua perkhidmatan sokongan perniagaan MARA melalui Program Pembangunan Keusahawanan (Latihan Keusahawanan, Program Pembangunan Standard Perniagaan, Program Pembangunan Pemasaran, Skim Pembiayaan Perniagaan dan Penyewaan Infrastruktur Perniagaan). Kesemua peserta kajian yang dipilih dianggap sebagai pakar-pakar yang boleh memberi pengetahuan dan maklumat yang diperlukan berasaskan kepada keperluan objektif kajian (Kuratko \& Hodgetts 2001).

Jadual 1 menunjukkan peserta kajian daripada ketiga-tiga kumpulan ini dikelompokkan menjadi 5 kes yang mana setiap kes terdiri daripada (1) orang Pegawai MARA di peringkat negeri, satu (1) orang Pegawai MARA di peringkat daerah dan satu (1) buah syarikat PKS.

JADUAL 1. Profil peserta kajian

\begin{tabular}{llll}
\hline No Kes & Peserta Kajian dan Jawatan & $\begin{array}{l}\text { Singkatan/ } \\
\text { Pusat/Lokasi }\end{array}$ & $\begin{array}{l}\text { Tahun } \\
\text { Berkhidmat/Tahun } \\
\text { Beroperasi }\end{array}$ \\
\hline Kes 1 & Pegawai MARA Daerah & PMD A & 8 tahun \\
& Penolong Pegawai Ehwal Ekonomi & PMN A & 3 tahun \\
& Pemilik Syarikat A & Selangor & 10 tahun \\
Kes 2 & Ketua Penolong Pengarah & PMN A & 11 tahun \\
& Pegawai MARA Daerah & PMD B & 5 tahun \\
& Pemilik Syarikat B & Selangor & 6 tahun \\
Kes 3 & Pegawai MARA Daerah & PMD C & 33 tahun \\
& Penolong Pegawai MARA Daerah & PPMD C & 23 tahun \\
\multirow{4}{*}{ Kes 4 } & Pemilik Syarikat C & Terengganu & 18 tahun \\
& Pegawai MARA Daerah & PMD C & 33 tahun \\
& Penolong Pegawai MARA Daerah & PPMD C & 23 tahun \\
Kes 5 & Pemilik Syarikat D & Terengganu & 40 tahun \\
& Penolong Pegawai MARA Daerah I & PMD B & 9 tahun \\
& Penolong Pegawai MARA Daerah II & PPMD B & 8 tahun \\
& Pemilik Syarikat E & Selangor & 20 tahun \\
\hline
\end{tabular}

Kajian ini menggunakan temu bual sebagai kaedah pengumpulan data dengan mengguna pakai protokol temu bual yang dibangunkan berdasarkan kerangka konseptual kajian. Menurut Merriam (2009), temu bual dalam penyelidikan kualitatif bertujuan untuk mendapatkan gambaran dan tema utama dalam dapatan kajian. Matlamat utama temu bual ialah untuk memahami apa yang diperkatakan oleh mereka yang ditemu bual (Plas \& Kvale 1996). Menurut Merriam (2009) lagi, temu bual adalah merupakan teknik yang berkesan untuk mendapatkan maklumat kajian secara intensif. Temu bual juga merupakan kaedah yang paling banyak digunakan dalam pengumpulan data dan dilaksanakan sama ada secara separa berstruktur atau tidak berstruktur (Holloway \& Wheeler 2002).

Temu bual telah dilaksanakan secara bersemuka dengan setiap peserta kajian dan belaku secara one-off atau pun berulang bergantung kepada keperluan bagi mencapai objektif kajian. Thorne dan Darbyshire (2005) mencadangkan agar penyelidik menggunakan konsep ketepuan data (data saturation) sebagai titik penamat pengumpulan data. Ketepuan data merujuk kepada keadaan di mana tidak ada lagi maklumat baru yang dapat dikumpulkan atau muncul daripada penambahan temu bual baharu dengan persampelan selanjutnya. Dalam kajian ini, pengumpulan data ditamatkan setelah peserta daripada kes terkemudian yang ditemu bual memberikan maklumat yang sama yakni perulangan dapatan kajian yang sama dan tiada sebarang maklumat baru diperoleh atau muncul hasil daripada temu bual tersebut. Keadaan yang dinyatakan di atas berlaku selepas temu bual kes 4 dan temu bual diteruskan untuk kes 5 .

Proses temubual dan analisis data dibuat secara lelaran (iterative) dan selari mengikut keperluan kerja-kerja data analisis. Proses analisis data kajian termasuk menyalin data temubual dalam bentuk transkrip dan menyusunnya secara sistematik. Transkrip temubual dianalisis dengan menggunakan teknik analisis data berperingkat sepertimana yang dicadangkan oleh Merriam (2009) yang bermula dari proses pengekodan terbuka (open coding), iaitu ayat atau perenggan yang berkaitan dengan sesuatu perkara yang dikaji telah dikodkan. Seterusnya, kod tersebut dikumpul dan digabungkan mengikut tema atau kategori yang mana kod-kod diagregatkan berdasarkan persamaan ciri, iaitu proses pengekodan paksi (axial coding).

\section{DAPATAN KAJIAN}

Data untuk lima kes telah dianalisis dari aspek dimensi interaksi antara ejen dan syarikat PKS dalam proses penyampaian perkhidmatan sokongan sosial. Analisis interaksi penyedia dan penerima adalah mengikut peringkat pembangunan syarikat PKS. Kajian ini mendapati bahawa proses interaksi dalam perkhidmatan berlaku di setiap 
peringkat pembangunan syarikat PKS iaitu tahap keusahawanan, tahap kelompokan, tahap pemformalan dan tahap perluasan.

Tahap Keusahawanan Terdapat dua dimensi interaksi di antara ejen dan syarikat PKS di dalam perkhidmatan sokongan sosial di tahap keusahawanan dalam hayat organisasi, iaitu saling komited dan hubungan informatif.

a. Saling komited

Dimensi interaksi yang pertama di tahap keusahawanan ini adalah saling komited yang merujuk kepada ejen sebagai penyedia perkhidmatan sokongan sosial dan syarikat PKS sebagai penerima perkhidmatan sokongan sosial memberikan tumpuan sepenuhnya untuk melaksanakan peranan masing-masing ketika berinteraksi di dalam perkhidmatan sokongan sosial untuk pembangunan syarikat PKS. Di antara sub-ciri saling komited adalah patuh arahan yang merujuk kepada pihak ejen dan syarikat PKS yang patuh kepada arahan yang dikeluarkan oleh kedua-dua belah pihak semasa proses perkhidmatan berlaku untuk memastikan kelancaran perjalanan program yang disediakan oleh organisasi penyedia.

Pernyataan dua Pegawai MARA dan usahawan syarikat A menunjukkan ciri-ciri patuh arahan ini:

Usahawan perlu membuat bayaran yuran penyertaan dan seterusnya di sepanjang program tersebut, usahawan perlu mengikut peraturan program yang telah ditetapkan oleh MARA contohnya mereka kena menepati waktu buka dan tutup gerai pameran.

PMD A

Saya beritahu dengan usahawan, yang dia kena perbaiki pengurusan syarikatnya. Saya beritahu dia, mungkin dia perlukan bimbingan secara terus, one-to-one, jadi saya minta dia ke pejabat MARA untuk buka fail. Saya beritahu dia yang saya sedia beri khidmat.

PMN A

Pegawai MARA mendapati bahawa tahap pengurusan syarikat saya perlu ditambahbaik. Dia jumpa saya dan beritahu yang pengurusan syarikat ini perlu tambahbaik, dan bertanya apa yang syarikat perlukan. Pegawai mencadangkan agar saya diberikan bimbingan lanjutan. Saya pun setuju.

Pemilik Syarikat A

b. Hubungan informatif

Dimensi seterusnya di tahap keusahawanan ini adalah hubungan informatif di antara ejen dan syarikat PKS khususnya dalam memberi dan menerima maklumat yang lengkap di antara kedua-dua belah pihak untuk merealisasikan proses perkhidmatan sokongan sosial. Ejen dan syarikat PKS memerlukan maklumat yang lengkap untuk merancang, melaksana dan membuat keputusan dalam perkhidmatan sokongan sosial. Tambahan pula, ejen dan syarikat PKS menggunakan dua bentuk medium komunikasi untuk melengkapkan hubungan informatif iaitu melalui media konvensional seperti membuat perjumpaan dan lawatan ke premis perniagaan syarikat PKS, serta berkomunikasi melalui telefon, surat dan media baharu seperti laman portal rasmi organisasi penyedia perkhidmatan sokongan sosial, termasuk media sosial seperti whatsapp, facebook, instagram dan sebagainya. Penggunaan medium komunikasi yang bersesuaian antara ejen dan syarikat PKS dapat memastikan maklumat yang diperlukan dapat disalurkan secara masa sebenar (real time) mengikut keperluan dan maklumat tersebut difahami dengan jelas oleh kedua-dua belah pihak penyedia dan penerima perkhidmatan.

Dua orang pegawai MARA dan usahawan syarikat A yang menerima perkhidmatan menjelaskan medium komunikasi antara pihak MARA dan syarikat PKS:

Kebanyakan usahawan, termasuk usahawan ini mendapat tahu tentang maklumat kemudahan MARA terutama mengenai Pusat Usahawan MARA (PUSMA) melalui laman facebook PUSMA. Selain itu juga pihak MARA ada menyediakan risalah-risalah yang mengandungi jadual tahunan kursus-kursus, program, latihan, seminar dan sebagainya.

$P M D A$

Selain daripada laman web MARA yang sentiasa memberi maklumat kemudahan MARA, kami di Pejabat MARA Daerah Shah Alam juga mempunyai laman facebook sendiri untuk penyebaran maklumat aktiviti dan program Pejabat MARA Daerah Shah Alam.

$P M N A$

Saya sebagai usahawan sentiasa mendapat maklumat berkenaan dengan skim dan program MARA. Bermula daripada saya mendapat bantuan di bawah Program Usahawan Teknikal (PUTEK), saya mula merapatkan diri dengan MARA dan saya nampak banyak ruang yang MARA boleh bantu saya. 
Tahap Kelompokan Terdapat lima dimensi interaksi di antara ejen dan syarikat PKS di dalam perkhidmatan sokongan sosial yang berlaku di tahap kelompokan ini, iaitu, saling komited, hubungan informatif, saling kebergantungan, saling yakin dan percaya, dan kesinambungan.

\section{c. Saling komited}

Dimensi interaksi yang pertama di tahap kelompokan ini adalah saling komited yang merujuk kepada ejen sebagai penyedia perkhidmatan sokongan sosial dan syarikat PKS sebagai penerima perkhidmatan sokongan sosial memberikan tumpuan sepenuhnya untuk melaksanakan peranan masing-masing. Sub-ciri saling komited yang pertama adalah penglibatan terus kedua-dua belah pihak iaitu ejen dan terutamanya usahawan syarikat PKS tanpa mewakilkan kepada pihak ketiga seperti pengurus atau pekerja dalam pelaksanaan program perkhidmatan sokongan sosial seperti menghadiri kursus atau latihan, mengadakan perbincangan di antara kedua belah pihak dan menjalankan urusan berkaitan perkhidmatan sokongan sosial yang disediakan untuk syarikat PKS. Penglibatan terus ini dapat mempertingkatkan komitmen dalam kalangan ejen dan syarikat PKS dalam memastikan kelancaran proses interaksi dalam penyampaian perkhidmatan sokongan sosial. Sub-ciri saling komited yang kedua adalah sikap proaktif ejen dan syarikat PKS samada di peringkat individu atau organisasi dalam merangka atau melakukan sesuatu tindakan lebih awal sebelum berlakunya sesuatu perkara yang sememangnya memerlukan tindakan berkenaan.

\section{d. Hubungan informatif}

Dimensi interaksi seterusnya di tahap kelompokan ini adalah hubungan informatif yang berterusan di antara ejen dan syarikat PKS khususnya dalam memberi dan menerima maklumat yang lengkap di antara kedua-dua belah pihak untuk merealisasikan proses perkhidmatan sokongan sosial. Ejen dan syarikat PKS memerlukan maklumat yang lengkap untuk merancang, melaksana dan membuat keputusan yang lebih kerap di dalam proses perkhidmatan sokongan sosial yang disediakan oleh organisasi penyedia perkhidmatan sokongan sosial. Dalam tahap kelompokan ini, ejen dan syarikat PKS masih terus menggunakan dua bentuk medium komunikasi untuk melengkapkan hubungan informatif iaitu media konvensional seperti membuat perjumpaan dan lawatan ke premis perniagaan syarikat PKS, serta berkomunikasi melalui telefon, surat dan media baharu seperti laman portal rasmi organisasi penyedia perkhidmatan sokongan sosial termasuk media sosial seperti whatsapp, facebook, instagram dan yang lainnya. Penggunaan medium komunikasi yang bersesuaian di antara ejen dan syarikat PKS dapat memastikan maklumat yang perlu disampaikan dapat disalurkan dan difahami dengan jelas oleh kedua-dua belah pihak.

\section{e. Saling kebergantungan}

Saling kebergantungan adalah dimensi interaksi yang ketiga di tahap kelompokan ini yang merujuk kepada aktiviti di mana ejen dan syarikat PKS yang memerlukan di antara satu sama lain dalam melengkapkan proses perkhidmatan sokongan sosial. Di tahap kelompokan ini, saling kebergantungan di antara ejen dan syarikat PKS tertumpu kepada program perkhidmatan sokongan sosial berbentuk standard seperti latihan perniagaan, pembangunan standard perniagaan, promosi dan pemasaran secara jangka pendek iaitu khusus kepada program berkenaan sahaja. Dimensi interaksi ini dapat memastikan proses perkhidmatan sokongan sosial berjalan dengan lancar.

\section{f. Saling yakin dan percaya}

Saling yakin dan percaya merupakan dimensi interaksi yang keempat di tahap kelompokan ini yang merujuk kepada pengukuhan hubungan dan interaksi yang telah terjalin di antara ejen dan syarikat PKS di tahap pembangunan syarikat PKS sebelum ini iaitu tahap keusahawanan. Keyakinan dan kepercayaan di antara ejen dan syarikat PKS amat bergantung kepada hubungan dan interaksi terus di antara kedua-dua belah pihak. Dimensi interaksi di tahap kelompokan ini banyak bergantung kepada tindakan proaktif pihak ejen dan terutamanya usahawan syarikat PKS yang perlu berusaha serta lebih kerap berurusan dengan ejen berkenaan.

\section{g. Kesinambungan}

Kesinambungan perkhidmatan sokongan sosial adalah dimensi interaksi yang kelima di tahap kelompokan ini merujuk kepada perkhidmatan sokongan sosial yang diberikan secara berterusan kepada syarikat PKS oleh ejen. Kesinambungan perkhidmatan sokongan sosial ini dapat memastikan matlamat ejen dan syarikat PKS dicapai secara sistematik dan sekaligus menjayakan keseluruhan proses perkhidmatan sokongan sosial untuk pembangunan syarikat PKS. 
Tahap Pemformalan Terdapat empat dimensi interaksi di antara ejen dan syarikat PKS di dalam perkhidmatan sokongan sosial di tahap pemformalan dalam kitaran hayat syarikat PKS ini iaitu a) ejen dan penerima perkhidmatan sokongan sosial yang saling aktif, b) hubungan daripada peringkat awal perancangan perkhidmatan sokongan sosial terpilih di antara ejen dan penerima perkhidmatan sokongan sosial, c) pelaksanaan program secara berkumpulan dan d) interaksi pelbagai peringkat di antara ejen di dalam organisasi penyedia perkhidmatan sokongan sosial dalam melaksanakan perkhidmatan kepada penerima iaitu syarikat PKS.

\section{a. Saling aktif}

Dimensi interaksi yang pertama di tahap pemformalan ini adalah penglibatan saling aktif yang berlaku di sepanjang proses interaksi perkhidmatan sokongan sosial di antara ejen dan syarikat PKS untuk memastikan perkhidmatan berjalan dengan lancar dan mengelakkan daripada objektif asal perkhidmatan yang telah dipersetujui oleh kedua-dua belah pihak iaitu ejen dan syarikat PKS menjadi tersasar. Ejen dan syarikat PKS sentiasa memaklumkan antara satu sama lain mengenai aktiviti atau program masing-masing. Komunikasi di antara ejen dan syarikat PKS adalah kerap terutamanya daripada pihak syarikat PKS yang sentiasa mengemaskini makluman kepada ejen masing-masing mengenai perkembangan perniagaan mereka.

Berikut adalah pernyataan Pegawai MARA dan usahawan syarikat B yang menunjukkan penglibatan yang saling aktif kedua-dua pihak:

Biasanya dia [usahawan syarikat B] selalu bergabung dengan usahawan fesyen, usahawan kecantikan dan usahawan spa buat satu program khas tapi saya [Pegawai MARA] memang tidak sempat ikut program dia walaupun memang dia menjemput saya dalam program yang dijalankan oleh syarikat dia.

PMD B

Perhubungan komunikasi kami [Pegawai MARA] dengan usahawan syarikat ini agak kerap kerana beliau akan sentiasa memaklumkan kepada pihak kami sekiranya terdapat perkhidmatan syarikat yang terbaharu termasuk program promosi yang dijalankan oleh syarikat untuk disebarkan melalui media MARA.

PMN A

Biasanya saya [usahawan syarikat ini] akan whatsapp personally ke Pegawai MARA. Saya tidak akan hanya mendengar dari orang lain. Saya akan tanya bulan ini ada tak program untuk diikuti? Bulan depan ada juga tak program? Dalam masa terdekat ini ada tak program? Saya suka jadi orang yang mula-mula dapat tahu maklumat.

Pemilik Syarikat B

b. Hubungan di peringkat awal program

Dimensi interaksi yang kedua pada tahap pemformalan ini adalah hubungan di peringkat awal iaitu sebelum perancangan program di antara ejen dan penerima perkhidmatan sokongan sosial. Walau bagaimanapun, penglibatan syarikat PKS sebagai penerima perkhidmatan sokongan sosial di peringkat awal program adalah terhad kepada program-program tertentu sahaja. Di antara program yang melibatkan hubungan di peringkat awal program adalah program pembangunan standard perniagaan iaitu syarikat PKS sebagai penerima perkhidmatan sokongan sosial di beri pilihan oleh ejen untuk memilih perunding sama ada untuk bimbingan perniagaan mahupun untuk tujuan pemiawaian seperti persijilan halal, HACCP, GMP, ISO dan sebagainya. Hubungan di peringkat awal di antara ejen dan penerima perkhidmatan adalah perlu bagi menentukan keserasian di antara pihak ketiga yang dilantik oleh organisasi penyedia perkhidmatan sokongan sosial untuk melaksanakan sebahagian daripada perkhidmatan sokongan sosial yang memerlukan kepakaran khusus dari segi profesional dan teknikal.

c. Pelaksanaan program secara berkumpulan

Dimensi interaksi yang ketiga di tahap pemformalan ini adalah pelaksanaan program secara berkumpulan oleh organisasi penyedia perkhidmatan sokongan sosial yang melibatkan penerima secara berkumpulan selain daripada penerima secara individu. Antara program perkhidmatan sokongan sosial yang dilaksanakan secara berkumpulan yang melibatkan syarikat PKS di tahap pemformalan ini sebagai penerima secara berkumpulan adalah latihan keusahawanan peringkat pertengahan iaitu kursus, latihan, seminar yang menjurus kepada bidang perniagaan tertentu seperti spa dan kecantikan. Selain itu, program pembangunan pemasaran seperti ekspo, pameran, dan pembangunan standard perniagaan secara berkumpulan untuk mendapatkan persijilan halal, GMP, HACCP, ISO, serta khidmat nasihat perniagaan secara berkumpulan seperti perakaunan berkomputer, penyewa-penyewa premis perniagaan dan sebagainya.

d. Interaksi pelbagai peringkat antara ejen dan penerima perkhidmatan sokongan sosial

Dimensi interaksi yang keempat di tahap pemformalan ini adalah interaksi pelbagai peringkat dalam kalangan ejen organisasi penyedia perkhidmatan sokongan sosial di dalam proses perkhidmatan sokongan sosial. Interaksi tersebut berlaku secara intra-organisasi khususnya apabila ejen perlu mendapatkan kelulusan program terlebih 
dahulu daripada pihak atasan organisasi sebelum melaksanakannya. Terdapat juga interaksi antara organisasi iaitu di antara ejen organisasi penyedia perkhidmatan sokongan sosial dengan pihak luar dalam proses memberi perkhidmatan sokongan sosial untuk syarikat PKS. Seterusnya, interaksi yang sama oleh syarikat PKS sebagai penerima juga berlaku terutamanya apabila syarikat PKS ini berurusan dengan pelbagai peringkat ejen secara intra organisasi (Pegawai MARA Daerah dan Negeri) dan juga pihak luar dalam menyempurnakan proses perkhidmatan sokongan sosial.

Tahap Perluasan Terdapat empat dimensi interaksi di antara ejen dan syarikat PKS di dalam perkhidmatan sokongan sosial di tahap perluasan ini iaitu ejen dan penerima perkhidmatan yang saling aktif, hubungan yang berterusan di antara ejen yang silih berganti dengan penerima perkhidmatan, saling kebergantungan dan interaksi pelbagai peringkat di antara ejen dan usahawan syarikat PKS serta organisasi lain.

\section{a. Saling aktif}

Dimensi interaksi yang pertama di tahap perluasan ini adalah penglibatan saling aktif di antara ejen dan syarikat PKS untuk mencari penyelesaian ke atas isu dan masalah berskala besar yang dihadapi oleh syarikat PKS dari semasa ke semasa, meningkatkan lagi ketrampilan teknologi syarikat PKS dan juga untuk membolehkan syarikat PKS sentiasa mempunyai daya saing yang tinggi di dalam industri yang diceburinya. Ejen dan syarikat PKS di tahap perluasan ini mempunyai penglibatan saling aktif yang tinggi berbanding dengan peringkat pembangunan syarikat PKS sebelum ini. Selain itu, ejen sentiasa mengemaskini maklumat berhubung program perkhidmatan sokongan sosial yang baharu diperkenalkan oleh organisasi penyedia kepada syarikat PKS berkenaan. Interaksi di antara ejen dan syarikat PKS berlaku secara kerap terutamanya apabila terdapat isu dan masalah semasa syarikat PKS yang perlu diselesaikan segera. Penglibatan secara aktif berlaku di sepanjang proses interaksi perkhidmatan sokongan sosial di tahap perluasan ini.

b. Hubungan yang berterusan dengan ejen bersilih ganti

Dimensi interaksi yang kedua di tahap perluasan ini adalah hubungan yang berterusan di antara ejen bersilih ganti dan usahawan syarikat PKS sebagai penerima perkhidmatan. Kajian ini mendapati bahawa usahawan syarikat PKS di tahap perluasan ini berjaya mengekalkan hubungan yang berterusan dengan ejen selama berurusan dengan organisasi penyedia perkhidmatan sokongan sosial. Keakraban hubungan ini membolehkan syarikat PKS sentiasa mendapat bimbingan dan tunjuk ajar yang sewajarnya daripada ejen-ejen organisasi penyedia perkhidmatan sokongan sosial walaupun berlaku pertukaran ejen dari semasa ke semasa. Seterusnya, berlaku perulangan proses dalam perkhidmatan sokongan sosial khususnya dalam membina semula hubungan di antara ejen baharu dan syarikat PKS sebelum perkhidmatan sokongan sosial sedia ada diteruskan. Walau bagaimanapun, terdapat pengulangan proses interaksi semasa tempoh peralihan daripada ejen terdahulu kepada ejen baharu; namun keadaan tersebut adalah bersifat sementara dan tidak menjejaskan proses perkhidmatan secara keseluruhannya. Ini adalah kerana proses penyesuaian diri di antara ejen baharu dan syarikat PKS tersebut berjalan lancar dengan bantuan ejen-ejen sedia ada di semua peringkat organisasi penyedia perkhidmatan.

\section{c. Saling kebergantungan}

Dimensi interaksi yang ketiga di tahap perluasan ini adalah saling kebergantungan yang merujuk kepada aktiviti di mana ejen dan syarikat PKS yang memerlukan di antara satu sama lain dalam melengkapkan proses interaksi perkhidmatan sokongan sosial untuk pembangunan syarikat PKS. Di tahap perluasan ini, saling kebergantungan di antara ejen dan syarikat PKS bertumpu kepada pelbagai program perkhidmatan sokongan sosial berbentuk pelangganan secara berterusan dalam jangka panjang. Saling kebergantungan di antara kedua-dua belah pihak ini menjadi semakin tinggi di peringkat perluasan syarikat ini disebabkan oleh organisasi penyedia telah memilih syarikat PKS berkenaan sebagai syarikat PKS tunjang, manakala pihak syarikat PKS pula masih memerlukan perkhidmatan sokongan sosial untuk terus menyokong pembangunan kemandirian syarikat mereka di masa akan datang.

Kedua-dua ejen dan usahawan syarikat ini saling bergantung untuk memastikan objektif perkhidmatan sokongan sosial tercapai dengan jayanya dan seterusnya memberikan hasil yang positif kepada mereka. Dimensi interaksi ini penting dalam memastikan proses penyampaian perkhidmatan sokongan sosial terus berjalan dengan lancar. Hubungan saling kebergantungan beransur berkurangan apabila syarikat PKS telah mampu berdikari, namun tiada tempoh yang standard untuk syarikat PKS mencapai tahap tersebut. Seterusnya, syarikat PKS di tahap perluasan yang mampu berdikari tidak lagi bergantung sepenuhnya kepada organisasi penyedia perkhidmatan sokongan sosial dalam mendapatkan perkhidmatan sokongan sosial bagi memenuhi keperluan semasa syarikat PKS mereka. Sebagai contoh ialah pemilik Syarikat D yang tidak lagi menerima perkhidmatan sosial MARA selama lapan tahun setelah berupaya berdikari.

Walau bagaimanapun, hubungan saling kebergantungan di antara ejen dan syarikat PKS kembali wujud apabila syarikat perlu mendapatkan perkhidmatan sokongan sosial untuk meneroka lebih jauh bagi memasarkan 
produk atau perkhidmatan keluaran syarikat mereka. Begitu juga apabila syarikat PKS berhasrat untuk menjalankan penyumberluaran pengeluaran produk syarikat khususnya di peringkat serantau dan antarabangsa. Ini bermakna, usahawan syarikat PKS akan kembali bergantung kepada perkhidmatan sokongan sosial apabila mereka memerlukan kompetensi dan kapasiti baharu bagi menyokong pembangunan syarikat yang mapan

Sebagai contoh, apabila Syarikat D bercadang untuk memohon pembiayaan peniagaan bagi menembusi pasaran luar negara, hubungan saling kebergantungan kembali wujud, seperti yang dinyatakan oleh dua Pegawai MARA dan usahawan syarikat ini:

Usahawan syarikat ini sedang dalam proses permohonan untuk mendapatkan perkhidmatan rekabentuk beg plastik eksklusif untuk mengisi pakaian yang telah dijahit melalui program Pembangunan Standard Perniagaan (PSP).

PPMD C

Pihak MARA membantu syarikat ini untuk menerokai pasaran yang lebih luas iaitu ke luar negara dan juga bantuan penambahan mesin dan peralatan jahitan yang berteknologi canggih.

PMD C

Saya juga menjalankan penyelidikan secara dalaman syarikat untuk meningkatkan kemahiran khususnya dalam pembuatan kot dan pakaian rasmi. Di antara kaedahnya adalah melalui pemerhatian pemakaian pakaian, perekayasaan melalui pengesanan produk iaitu membuka semula jahitan pakaian yang telah siap yang dibeli secara pukal daripada pakaian terpakai dan sebagainya.

Pemilik Syarikat D

d. Interaksi pelbagai peringkat antara ejen dan penerima perkhidmatan sokongan sosial

Akhirnya, dimensi interaksi yang keempat di tahap perluasan ini adalah interaksi pelbagai peringkat dalam kalangan ejen organisasi penyedia perkhidmatan sokongan sosial di dalam proses interaksi perkhidmatan sokongan sosial. Interaksi di antara ejen dan usahawan syarikat ini berlaku di Pejabat MARA Daerah, Pusat Latihan Usahawan MARA (PUSMA) dan Ibu Pejabat MARA. Interaksi pelbagai peringkat secara intra organisasi berfokus kepada usahawan syarikat PKS berurusan terus dengan ejen yang menyelia program untuk mendapatkan perkhidmatan sokongan sosial di semua peringkat organisasi penyedia perkhidmatan sokongan sosial. Pada masa yang sama ejen dan usahawan syarikat PKS juga berinteraksi dengan ejen dan organisasi penyedia perkhidmatan sokongan sosial yang lain dalam menyelaras dan mendapatkan perkhidmatan sokongan sosial yang ditawarkan oleh agensi-agensi Kerajaan berkenaan yang tidak ditawarkan oleh MARA.

\section{PERBINCANGAN}

Kajian ini merumuskan bahawa proses interaksi antara penyedia-penerima perkhidmatan sokongan sosial berlaku di setiap peringkat pembangunan syarikat PKS. Seterusnya, wujud dimensi interaksi penyedia-penerima yang memiliki ciri-ciri yang sama dan berbeza di setiap peringkat pembangunan syarikat. Kajian ini mendapati berlaku proses interaksi dalam semua peringkat proses pembangunan syarikat PKS bagi membolehkan penawaran perkhidmatan oleh ejen penyedia perkhidmatan kepada pelanggan yang disasarkan. Dapatan kajian ini menjana model baharu proses interaksi penerima-penyedia perkhidmatan sokongan sosial, seperti yang ditunjukkan dalam Rajah 2.

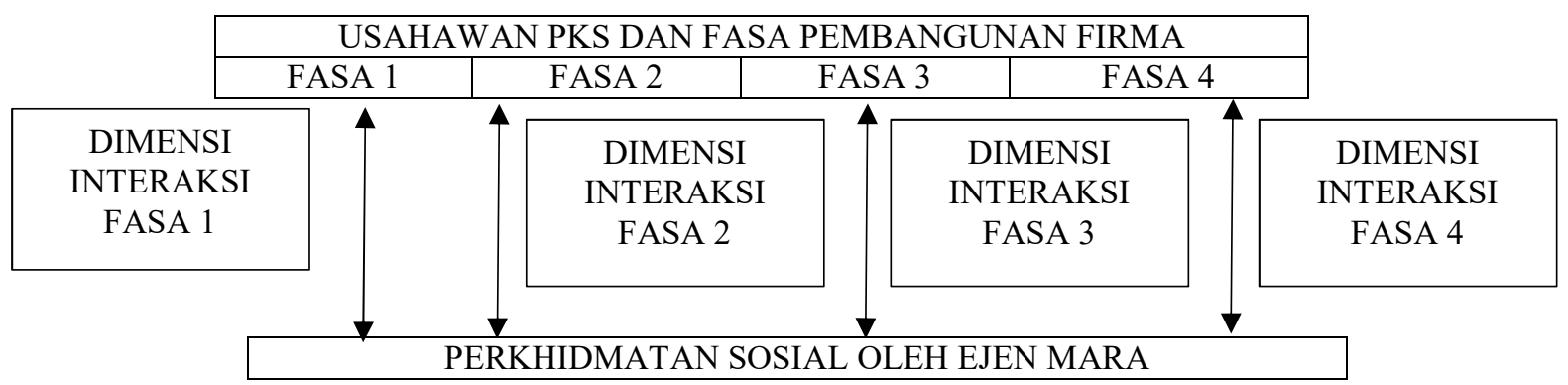

RAJAH 2. Model baharu dimensi interaksi penyedia-penerima perkhidmatan sokongan sosial dalam pembangunan syarikat PKS

Model baharu proses interaksi penerima-penyedia perkhidmatan sokongan sosial untuk pembangunan syarikat PKS ini menunjukkan bahawa di tahap keusahawanan terdapat dua dimensi interaksi penyedia-penerima 
perkhidmatan sokongan sosial iaitu saling komited dengan sub ciri patuh arahan dan hubungan informatif dengan sub ciri maklumat lengkap dan media komunikasi. Penglibatan yang aktif dan saling bertanggungjawab daripada kedua-dua belah pihak akan menghasilkan nilai bersama (Osborne 2018) seperti yang berlaku dalam tahap kelompokan iaitu saling komited dengan sub-ciri penglibatan secara terus dan proaktif, hubungan informatif dengan sub ciri maklumat lengkap dan media komunikasi, saling kebergantungan, saling percaya dan yakin dan kesinambungan merupakan nilai yang terhasil daripada hubungan dua hala ini.

Manakala dimensi interaksi di tahap pemformalan adalah saling aktif, hubungan di peringkat awal program, pelaksanaan program secara berkumpulan dan interaksi pelbagai peringkat. Akhirnya, dimensi interaksi di tahap perluasan adalah saling aktif, hubungan yang berterusan dengan ejen bersilih ganti, saling kebergantungan dan interaksi pelbagai peringkat. Dimensi interaksi ini dirumuskan melalui Jadual 2.0.

Peranan ejen dalam proses interaksi perkhidmatan sokongan sosial bertambah dari semasa ke semasa selaras dengan peringkat pembangunan syarikat PKS, jenis program perkhidmatan sokongan sosial yang dikendalikan dan bilangan syarikat PKS yang berada di bawah kawal selia ejen berkenaan. Dalam melaksanakan peranan sebagai ejen, berlaku interaksi pelbagai hala antara ejen yang dipengaruhi oleh pembuatan keputusan di pelbagai peringkat dalam organisasi penyedia perkhidmatan sokongan sosial. Peranan ejen adalah berdasarkan kedudukan ejen dalam struktur organisasi penyedia perkhidmatan sokongan sosial berdasarkan penghuraian kerja, gred jawatan dan tempat bertugas.

JADUAL 2. Ringkasan Dimensi Interaksi Penyedia-Penerima Perkhidmatan Sosial Mengikut Peringkat Pembangunan

\begin{tabular}{|c|c|c|c|c|}
\hline $\begin{array}{l}\text { Fasa } \\
\text { Pembangunan } \\
\text { Syarikat PKS }\end{array}$ & $\begin{array}{l}\text { Tahap } \\
\text { Keusahawanan }\end{array}$ & Tahap Kelompokan & Tahap Pemformalan & Tahap Perluasan \\
\hline $\begin{array}{l}\text { Dimensi } \\
\text { interaksi }\end{array}$ & $\begin{array}{l}\text { - Saling komited } \\
\text { - Hubungan } \\
\text { informatif }\end{array}$ & $\begin{array}{l}\text { - Saling komited } \\
\text { - Hubungan } \\
\text { informatif } \\
\text { - Saling } \\
\text { kebergantungan } \\
\text { - Saling percaya dan } \\
\text { yakin } \\
\text { - Kesinambungan }\end{array}$ & $\begin{array}{l}\text { - Saling aktif } \\
\text { - Hubungan di } \\
\text { peringkat } \\
\text { awal program } \\
\text { - Pelaksanaan } \\
\text { program secara } \\
\text { berkumpulan } \\
\text { - Interaksi pelbagai } \\
\text { peringkat }\end{array}$ & $\begin{array}{l}\text { - Saling aktif } \\
\text { - Hubungan } \\
\text { berterusan dengan } \\
\text { ejen silih ganti } \\
\text { - Saling } \\
\text { kebergantungan } \\
\text { - Interaksi pelbagai } \\
\text { peringkat }\end{array}$ \\
\hline
\end{tabular}

Seterusnya hubungan antara ejen dan usahawan syarikat PKS bermula secara formal dan kemudiannya berubah kepada hubungan sosial apabila kedua-dua pihak tersebut saling berpuas hati dan percaya dan yakin antara satu sama lain (van de Walle 2018). Hubungan antara ejen dan usahawan syarikat PKS tidak mempunyai jangkamasa yang spesifik dan berkembang secara ubah ansur (evolving) mengikut keperluan kedua-dua belah pihak. Terdapat perulangan proses interaksi apabila berlaku pertukaran ejen tetapi proses interaksi tersebut dipercepatkan dengan bantuan ejen-ejen terdahulu dan sedia ada. Justeru, ejen dan syarikat PKS tidak mempunyai kuasa mutlak untuk menentukan hala tuju proses interaksi berkenaan.

Selain itu, peranan usahawan syarikat PKS sebagai penerima perkhidmatan sokongan sosial bertambah selaras dengan bilangan dan jenis program perkhidmatan sokongan sosial yang diterima oleh syarikat PKS berkenaan. Peningkatan tahap dalam pembangunan syarikat PKS juga turut menjadi penyumbang kepada peranan yang dimainkan oleh syarikat PKS dalam proses penyampaian perkhidmatan sokongan sosial. Interaksi antara usahawan syarikat PKS dan ejen berlaku secara berterusan di sepanjang proses interaksi perkhidmatan sokongan sosial terutamanya apabila program perkhidmatan sokongan sosial disesuaikan secara khusus berasaskan keperluan syarikat PKS berkenaan.

Walau bagaimanapun, penglibatan syarikat PKS dalam proses interaksi perkhidmatan sokongan sosial ini lebih bertumpu kepada hubungan secara individu syarikat PKS dengan satu atau lebih ejen dan hubungan di antara syarikat PKS yang menerima perkhidmatan sokongan sosial di peringkat pembangunan syarikat PKS adalah amat terhad. Penglibatan usahawan syarikat PKS dalam proses interaksi perkhidmatan sokongan sosial menjadi semakin berkurang apabila syarikat PKS berkenaan telah mampu berdikari dalam menjalankan aktiviti perniagaannya pada ketika itu. Bagaimanapun kebergantungan usahawan syarikat PKS kepada organisasi penyedia perkhidmatan sokongan sosial kembali intensif apabila syarikat PKS berkenaan melaksanakan projek yang lebih besar selepas itu. Justeru, nilai perkhidmatan ini kepada usahawan syarikat PKS dan juga organisasi penyedia perkhidmatan bergantung kepada interaksi yang dinamik dan pengalaman kedua-dua belah pihak (Grönroos 2011; Osborne 2018). Pelbagai dimensi interaksi dikenal pasti selaras dengan peningkatan peranan ejen dan usahawan syarikat PKS di dalam program perkhidmatan sokongan sosial yang juga berdasarkan peringkat pembangunan syarikat PKS berkenaan. Sesuatu perkhidmatan sokongan sosial mempunyai interaksi pelbagai hala di antara ejen dan syarikat PKS yang dipengaruhi oleh pembuatan keputusan pelbagai peringkat di dalam 
organisasi penyedia perkhidmatan sokongan sosial, mempunyai proses berbilang (multi process) dalam setiap peringkat pembangunan syarikat PKS.

Seterusnya proses interaksi amat bergantung kepada keserasian ejen dan usahawan syarikat PKS dalam menjalankan peranan masing-masing dalam mencapai objektif perkhidmatan sokongan sosial yang dipersetujui dan dihasratkan oleh kedua-dua belah pihak yang terlibat dalam proses interaksi ini. Sekiranya berlaku keadaan yang mana salah satu pihak gagal menyempurnakan peranan sepenuhnya maka berlaku pengabaian hubungan secara langsung kepada pihak satu lagi.

Berikutnya, pihak yang terabai mengambilalih pengemudian keadaan dan proses interaksi perkhidmatan sokongan sosial untuk melaksanakan tindakan remedi bagi memulihkan proses interaksi tersebut. Tindakan remedi yang diambil adalah seperti memperbaiki kegagalan dan menyelesaikan masalah dengan meminta maaf kepada salah satu pihak atau membayar pampasan (Van Vaerenbergh, Larivière \& Vermeir 2012). Keadaan ini menunjukkan terdapat darjah kebergantungan yang tinggi di antara ejen dan syarikat PKS di sepanjang proses perkhidmatan sokongan sosial berjalan. Hasil daripada analisis interaksi penyedia-penerima, dimensi interaksi ini dapat dirumuskan sebagai tiga dimensi utama.

Saling Kebergantungan Ejen dan syarikat PKS dalam perkhidmatan sokongan sosial saling bergantung di antara satu sama lain untuk memastikan kelancaran dan pencapaian matlamat yang diinginkan oleh kedua-dua belah pihak. Seterusnya, darjah kebergantungan ini semakin tinggi selaras dengan tempoh masa dan jenis perkhidmatan yang terlibat di antara pihak yang dinyatakan di atas.

Hubungan Simbiotik Hubungan simbiotik merujuk kepada hubungan yang saling memanfaatkan dan tidak menjejaskan kedudukan di antara penyedia perkhidmatan dan penerima perkhidmatan. Kajian ini juga mendapati bahawa hubungan simbiotik adalah merupakan di antara penyumbang faktor kejayaan proses interaksi dalam penyampaian perkhidmatan sokongan sosial.

Evolusi Dalam Perhubungan Proses interaksi dalam perkhidmatan sokongan sosial adalah merupakan hubungan berjangka panjang yang dijalinkan oleh penyedia perkhidmatan dan penerima perkhidmatan. Evolusi dalam perhubungan melibatkan tempoh masa yang panjang, melalui peringkat pembangunan syarikat PKS dan memerlukan komitmen yang tinggi di antara kedua-dua belah pihak.

\section{KESIMPULAN DAN IMPLIKASI KAJIAN}

Kesimpulannya, interaksi dalam proses penyampaian perkhidmatan sokongan sosial berkembang mengikut peringkat pembangunan syarikat PKS dan fasa proses penyampaian perkhidmatan sokongan sosial. Proses interaksi ini bergantung kepada jalinan hubungan terus yang wujud antara ejen sebagai penyedia perkhidmatan sokongan sosial dan usahawan syarikat PKS sebagai penerima perkhidmatan. Dapatan ini memberi sumbangan yang signifikan dalam membangun teori proses perkhidmatan dengan memperkembangkan fasa proses keusahawanan dalam model penyampaian perkhidmatan dalam konteks perkhidmatan sokongan sosial untuk pembangunan syarikat PKS.

Secara khususnya, penemuan dimensi interaksi dalam penyediaan proses perkhidmatan sokongan sosial untuk pembangunan syarikat PKS oleh organisasi penyedia perkhidmatan sokongan sosial memperkaya teori proses perkhidmatan dalam konteks perkhidmatan sokongan sosial. Dimensi baharu interaksi yang dikenal pasti dalam kajian ini dirangkumkan kepada tiga dimensi utama iaitu saling kebergantungan, hubungan simbiotik (hubungan yang membawa faedah dan keuntungan kedua-dua belah pihak) dan evolusi dalam perhubungan.

Penemuan dimensi interaksi penyedia-penerima perkhidmatan sokongan sosial ini juga menyumbang kepada amalan pengurusan kerana ia menjadi pengetahuan asas bagi menyokong pembangunan garis panduan untuk pelaksanaan perkhidmatan sokongan sosial yang lebih berkesan. Penemuan dimensi-dimensi interaksi ini membolehkan organisasi penyedia perkhidmatan sokongan sosial memperincikan peranan ejen mengikut huraian kerja serta mengenalpasti platform dan medium komunikasi untuk menyokong interaksi yang berkesan dengan kumpulan sasaran penerima perkhidmatan sokongan sosial. Manakala di pihak syarikat PKS pula, pemahaman proses dan dimensi interaksi dapat membantu usahawan syarikat PKS menggunakan perkhidmatan sosial sebagai daya tuil untuk memenuhi keperluan pembangunan syarikat mereka.

\section{PENGHARGAAN}

Penyelidikan ini dilaksanakan dengan biaya Geran Kerjasama Universiti-Industri, Social Support Service and SME Development: A Case Study of MARA Entrepreneur Development Program, USIM/MG/MARA/FEM/055012/70518. 


\section{RUJUKAN}

Bitner M.J., Fisk R.P. \& Brown S.W. 1993. Tracking the evolution of the services marketing literature. Journal of Retailing 69(1): 61-103.

Bowen, J. 1990. Development of a taxonomy of services to gain strategic marketing insights. Journal of the Academy of Marketing Science 18(1): 43-49.

Daft, R.L. 2013. Management. South Western Cengage Learning.

Fieldler, F.E. 1964. A contingency model of leadership effectiveness. Advances in Experimental Social Psychology 1: 149-90.

Gheduzzi E., Masella C., Morelli N. \& Graffigna G. 2020. Co-production as a co-creation or co-destruction process? An internal evaluation of a co- production exercise with family caregivers living in a rural and remote area. Research Square: 1-21.

Grönroos C. 1978. A service oriented approach to marketing of services. European Journal of Marketing 12(8): 588-601.

Grönroos, C. 2011. Value co-creation in service logic: A critical analysis. Marketing Theory 11(3): $279-301$.

Holloway, I. \& Wheeler S. 2002. Qualitative Research in Nursing. 2nd edition. Oxford: Wiley-Blackwell.

Iturralde, P., Heredia, L., de Rham, P. \& Lorena Mancero. 2007. How do social actors influence public policies?. ASOCAM Series Reflections and Lessons Learned: 12-13.

Jaumier, S. 2017. Preventing chiefs from being chiefs: An ethnography of a cooperative sheet-metal factory. Organization 24: 218-239.

Jawahar, I.M. \& Mclaughlin, G.L. 2001. Toward a descriptive stakeholder theory: An organizational life cycle approach. Academy of Management Review 26(3): 397-414.

Lamb, R. \& Kling, R. 2003. Reconceptualizing users as social actors in information systems research. MIS Quarterly 27(2): 197-236.

Lusch, R.F. \& Vargo, S.L. 2006. Service-dominant logic: Reactions, reflections and refinements. Marketing Theory 6(3): 281-288.

Kuratko, D.F. \& Hodgetts, R.M. 2001. Entrepreneurship: A Contemporary Approach. Australia: South-Western Thomson Learning.

Majlis Amanah Rakyat [MARA]. 2015. Laporan Tahunan MARA 2015. Available at https://www.mara.gov.my/en/index/mara-info/resources/publication/.

McLaughlin, K., Osborne, S. \& Chew, C. 2009. Developing the marketing function in U.K. public service organizations: The contribution of theory and practice. Public Money \& Management 29(1): 35-42.

Merriam, S.B. 2009. Qualitative Research: A Guide to Design and Implementation. San Francisco, CA: John Wiley \& Sons.

Miller, D. \& Friesen, P.H. 1980. Momentum and revolution in organizational adaptation. Academy of Management Journal 23: 591-614

Muhamad, N.S., Adham, K.A., Alias, M.A. \& Mohd Ali, K.A. 2018. How does transformative social service develop? Jurnal Pengurusan 54: 15-26.

Onkvisit S. \& Shaw J.J. 1991. Is services marketing "Really" different? Journal of Professional Services Marketing 7(2): 3-17.

Osborne, S. P. 2018. From public service-dominant logic to public service logic: Are public service organizations capable of co-production and value co-creation? Public Management Review 20(2): 225-231.

Patton, M.Q. 1990. Qualitative Evaluation and Research Methods. 2nd edition. US: Sage Publication.

Pettigrew, A.M. 1997. What is a processual analysis? Scandinavian Journal of Management 13(4): 337-348.

Plas, J.M. \& Kvale, S. 1996. Interviews: An Introduction to Qualitative Research Interviewing. Thousand Oaks, CA: Sage Publications.

Regan W.J. 1963. The service revolution. Journal of Marketing 47: 57-62.

Sampson, S.E. \& Froehle, C.M. 2006. Foundations and implications of a proposed unified services theory. Production and Operations Management 15(2): 329-343.

Shane, S. \& Venkataraman, S. 2000. The promise of entrepreneurship as a field of research. Academy of Management Review 25(1): 217-226.

SME Corporation Malaysia [SME Corp]. 2015. Laporan Tahunan SME 2014/2015. Available at https://www.smecorp.gov.my/index.php/en/resources/2015-12-21-11-07-06/sme-annual-report/book/72laporan-tahunan-pks-2014-2015/2-annual-report.

Strauss, A. \& Corbin, J. 1998. Basics of Qualitative Research: Techniques and Procedures for Developing Grounded Theory. Thousand Oaks, CA: Sage Publications, Inc.

Stern, P. N. 1980. Grounded theory methodology: Its uses and processes. Journal of Nursing Scholarship 12(1): 20-23.

Thorne, S. \& Darbyshire, P. 2005. Land mines in the field: A modest proposal for improving the craft of qualitative health research. Qualitative Health Research 15(8): 1105-1113. 
Van de Walle, S. 2016. When public services fail: A research agenda on public service failure. Journal of Service Management 27(5): 831-846.

Van de Walle, S. 2018. Explaining citizen satisfaction and dissatisfaction with public services. In The Palgrave Handbook of Public Administration and Management in Europe, edited by Ongaro, E. \& Van Thiels, 227241. London: Palgrave Macmillan.

Van Vaerenbergh, Y., Larivière, B. \& Vermeir, I. 2012. The impact of process recovery communication on customer satisfaction, repurchase intentions, and word-of-mouth intentions. Journal of Service Research 15(3): 262-279.

Vargo, S. 2008. Customer integration and value creation: Paradigmatic traps and perspectives. Journal of Service Research 11(2): 211-215.

Zeithaml V.A., Parasuraman A. \& Berry L.L. 1985. Problems and strategies in services marketing. Journal of Marketing 49: 33-46.

Shahrizin Abdul Sarhadat

Majlis Amanah Rakyat

Pejabat MARA Negeri Sabah

Tingkat 1, Lot 1 \& 2, Blok J

Ruang Singgah Mata 4, Asia City

88000 Kota Kinabalu, Sabah, MALAYSIA.

E-Mel: shahrizin@mara.gov.my

Khairul Akmaliah Adham

Fakulti Ekonomi dan Muamalat

Universiti Sains Islam Malaysia

71800 Nilai, Negeri Sembilan, MALAYSIA.

E-Mel: ka@usim.edu.my

Rosmah Mat Isa (penulis koresponden)

Fakulti Ekonomi dan Pengurusan

Universiti Kebangsaan Malaysia

43600 UKM Bangi, Selangor, MALAYSIA.

E-Mel: rosmah@ukm.edu.my 